\title{
A Case of Postpartum Hypopituitarism Accompanied by Cushing's Syndrome as a Result of an Adrenocortical Carcinoma
}

\author{
Mehmet SENCAN and Hatice Sebila DOKMETAS* \\ Department of Hematology, Faculty of Medicine, Cumhuriyet University, 58140 Sivas, Turkey \\ *Department of Endocrinology, Faculty of Medicine, Cumhuriyet University, 58140 Sivas, Turkey
}

\begin{abstract}
Sheehan's syndrome frequently causes hypopituitarism either immediately or after a delay of several years, depending on the degrees of postpartum ischemic pituitary necrosis. A 55 year-old woman whose last child was born $27 \mathrm{yr}$ ago with massive hemorrhage was diagnosed as postpartum hypopituitarism. She had deficiency of growth hormone, prolactin, gonadotropins and thyrotropin. However, she interestingly had apparent hypercortisolism without suppression response to the dexamethasone tests. We found an adrenal mass with distant metastases to the liver and lung while investigating the origin of the hypercortisolism. Hyperandrogenism and very high levels of $17 \alpha$ hydroxyprogesterone were present. Accordingly, the patient was diagnosed as hypopituitarism due to Sheehan's syndrome accompanied by Cushing's syndrome as a result of an adrenocortical carcinoma.
\end{abstract}

Key words: Sheehan's syndrome, Hypopituitarism, Hypercortisolism, Adrenocortical carcinoma

(Endocrine Journal 52: 219-222, 2005)

SHEEHAN'S syndrome occurs as a result of ischemic pituitary necrosis due to severe postpartum hemorrhage and is characterized by various degrees of hypopituitarism $[1,2]$. Sheehan's syndrome is a rare postpartum complication of pregnancy with better obstetric care in developed countries. Acute hypopituitarism may occur immediately after delivery or different degrees of pituitary failure may develop step by step over a long period $[2,3]$.

Adrenocortical carcinoma (ACC) is a relatively rare malignant tumor, which progresses rapidly within a few months. Adrenocortical carcinoma accounts for $0.05-0.2 \%$ of all cancers and its prevalence is 2 new cases per million of population per year $[4,5]$. Although it occurs in all ages, its peak periods are before the age of 5 years and 4 th to 5 th decades [5]. Patients

Received: March 17, 2004

Accepted: December 9, 2004

Correspondence to: Dr. H. Sebila DOKMETAS, Cumhuriyet Üniversitesi Tıp Fakültesi Endokrinoloji Bilim Dalı, 58140 Sivas, Turkey with adrenocortical carcinoma may show different endocrine syndromes depending on the secretion of tumor; hypercortisolism and hyperandrogenism are the most prevalent $[4,5]$.

In this report, a case with hypopituitarism due to Sheehan's syndrome accompanied by Cushing's syndrome as a result of an ACC is presented.

\section{Case}

A 55 year-old woman was admitted because of hypertension with duration of $20 \mathrm{yrs}$ and diabetes mellitus with duration of 5 yrs. She was using an ACE inhibitor, a diuretic and oral antidiabetics for her known illness. Review of her systems revealed that she had symptoms of anorexia, general fatigue, constipation, cold intolerance, sleep tendency and hirsutism being evident especially during the last 3-4 months. She had 3 children. She was $28 \mathrm{yr}$ of age when her last baby was born. She had suffered massive vaginal bleeding during delivery, failed to lactate in the early postpartum 
period and had secondary amenorrhea after delivery. On physical examination; her arterial blood pressure was $140 / 80 \mathrm{mmHg}$, she had facial plethora, supraclavicular fat pads, truncal obesity, and hepatomegaly. Her hirsutism score was 12 according to the FerrimannGallwey criteria. Complete blood count and biochemistry were normal except hyperglycemia, high erythrocyte sedimentation rate $(81 \mathrm{~mm} / 1$ hour $)$, and a mild normocytic-normochromic anemia (Hemoglobin: 11.9 $\mathrm{g} / \mathrm{dl})$.

Her hormone levels were found to be FSH: $<0.1 \mathrm{mIU} / 1$ (2.8-11.3), LH: $0.12 \mathrm{mIU} / 1$ (11.3-39.8), estradiol: $30.8 \mathrm{pg} / \mathrm{ml}(27-246)$, cortisol: $46.8 \mu \mathrm{g} / \mathrm{dl}$ (5-25), GH: $0.21 \mathrm{mIU} / \mathrm{ml}(>20)$, АCTH: $9.61 \mathrm{pg} / \mathrm{ml}$ (10-60), PRL: $10.7 \mathrm{ng} / \mathrm{ml}$ (2.5-17), TSH: $0.64 \mu \mathrm{IU} / \mathrm{ml}$ (0.49-4.67), free T3: $1.51 \mathrm{pg} / \mathrm{ml}(1.45-3.48)$ and free T4: $0.63 \mathrm{ng} / \mathrm{dl}(0.71-1.85)$. We evaluated her pituitary functions by GnRH and TRH tests (Table 1). Pituitary magnetic resonance imaging (MRI) revealed total empty sella. We concluded that she had Sheehan's syndrome since her past medical history was typical and she had hypopituitarism except high fasting morning plasma cortisol levels $(46.8 \mu \mathrm{g} / \mathrm{dl})$ and midnight plasma cortisol $(46.7 \mu \mathrm{g} / \mathrm{dl})$. After $2 \mathrm{mg}$ and $8 \mathrm{mg}$ dexamethasone suppression tests, sufficient suppression was not obtained for cortisol response $(46.2 \mu \mathrm{g} / \mathrm{dl}$ and $50 \mu \mathrm{g} / \mathrm{dl}$, respectively). Abdominal computed tomographic $(\mathrm{CT})$ scans revealed a $16 \times 15 \times 12.5 \mathrm{~cm}$ sized mass with irregular contours showing heterogeneous contrast and originating from the left adrenal gland (Fig. 1). Her liver's craniocaudal dimension was $22 \mathrm{~cm}$ and had a few metastatic lesions, the biggest being $5 \times 4 \mathrm{~cm}$ diameter (Fig. 1). There were diffuse nodular metastatic lesions in pulmonary parenchyma on thoracal CT scans (Fig. 2). The right adrenal gland and the other organs were normal. We evaluated her adrenal functions and the basal hormone levels were as follows: 11-deoxycortisol: $8.69 \mathrm{ng} / \mathrm{ml}(<8), 17 \alpha$

Table 1. Basal and after stimulation (by GnRH, TRH) values of cortisol, TSH, PRL, GH, LH and FSH

\begin{tabular}{lcccc}
\hline & Basal & 30 min & 60 min & 90 min \\
\hline Cortisol $(\mu \mathrm{g} / \mathrm{dl})$ & 46.8 & $>50$ & $>50$ & $>50$ \\
TSH $(\mu \mathrm{IU} / \mathrm{ml})$ & 0.64 & 3.16 & 2.51 & 1.96 \\
FSH $(\mathrm{mIU} / \mathrm{ml})$ & $<0.1$ & 0.11 & 0.17 & 0.15 \\
LH $(\mathrm{mIU} / \mathrm{ml})$ & 0.12 & 0.14 & 0.13 & 0.12 \\
PRL $(\mathrm{ng} / \mathrm{ml})$ & 10.7 & 12.7 & 18.1 & 11.7 \\
\hline
\end{tabular}

Normal values for Cortisol: 5-25, FSH: 2.8-11.3, LH: 11.3-39.8, PRL: 2.5-17, TSH: 0.49-4.67. hydroxyprogesterone (17 $\mathrm{OHP}): 57.68 \mathrm{ng} / \mathrm{ml}(0.23-$ 1.36), DHEAS: $981 \mu \mathrm{g} / \mathrm{dl}(35-430)$, androstenedione: $39.28 \mathrm{ng} / \mathrm{ml}(0.21-3.08)$, total testosterone: $1368 \mathrm{ng} / \mathrm{ml}$ (49-113), free testosterone: $45.80 \mathrm{pg} / \mathrm{ml}(0.30-1.73)$. Because she has had hypercortisolism, hyperandrogenism, high $17 \alpha \mathrm{OHP}$ levels and adrenal mass with liver and lung metastases, we concluded that the patient had an adrenocortical carcinoma in addition to Sheehan's syndrome.

We initiated levothyroxine treatment. The patient was discharged by her own consent to continue her treatment in another medical center, but we learned that she died two months after discharge from our hospital.

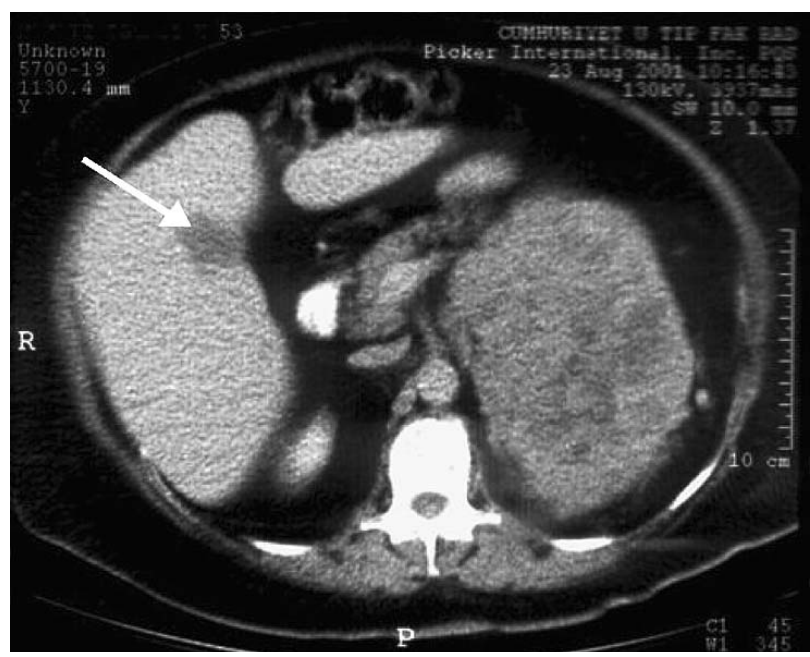

Fig. 1. The appearance of adrenal mass and metastatic lesion (white arrow) in liver on CT scan.

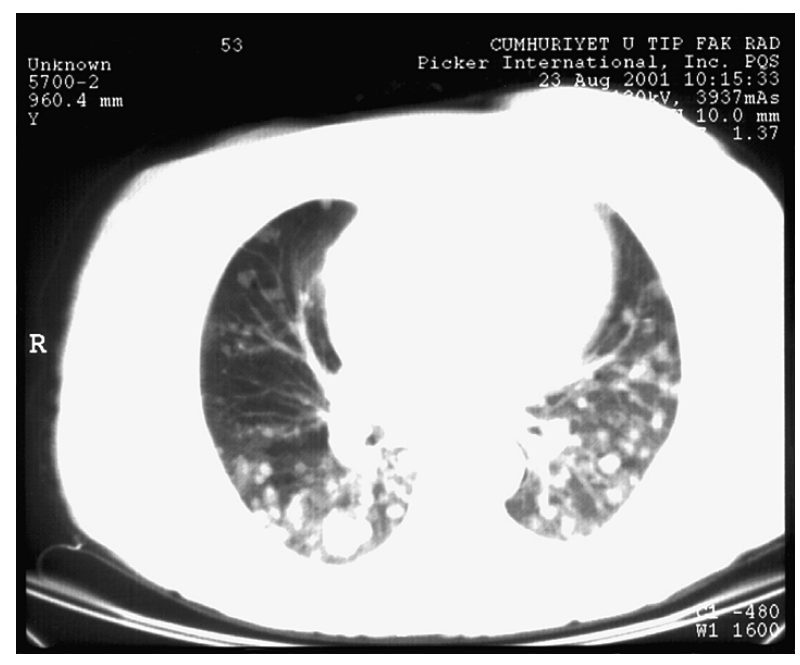

Fig. 2. The appearance of metastatic lesions in pulmonary parenchyma on thoracal CT scan. 


\section{Discussion}

One of the causes of hypopituitarism is the postpartum ischemic pituitary necrosis, which is called Sheehan's syndrome [1-3]. If a patient describes early menopause with the symptoms and clinical findings of hypothyroidism, this syndrome must be thought and a detailed obstetrical history must be taken to obtain some clues of postpartum pituitary necrosis. Because of the presence of such history in our case, we evaluated the pituitary function. Low GH levels and insufficient response of PRL to TRH test, secondary hypothyroidism and hypogonadism were present. Pituitary MRI of our case showing the total empty sella was compatible with Sheehan's syndrome. Although the clinical diagnosis of Sheehan's syndrome was based on the presented data, we interestingly found hypercortisolism and also its clinical findings. Moreover, we showed that there were insufficient suppression responses to low and high dose dexamethasone tests, and diurnal variation of cortisol secretion was lost. An adrenal mass with irregular contours showing heterogeneous contrast and its distant organ metastases to the liver and lung on the $\mathrm{CT}$ was found while investigating of the origin of hypercortisolism. Hyperandrogenism and its clinical findings such as hirsutism and very high levels of $17 \alpha \mathrm{OHP}$ were present. Accordingly, the patient was diagnosed with postpartum hypopituitarism accompanied by Cushing's syndrome as a result of an ACC. In the review of literature, there was only one case report who suffered from both Sheehan's syndrome and Cushing's syndrome and differing from our case, hypercortisolism in that case was a pituitary $\mathrm{ACTH}$-secreting tumor, not an adrenal source as in our case (6).

Partial or total empty sella is a characteristic finding of Sheehan's syndrome [1,2]. The reasons for secondary empty sella are surgical treatment, radiotherapy, spontaneous infarction of pituitary tumors, Sheehan's syndrome, lymphocytic hypophysitis, levothyroxine therapy in patient with primary hypothyroidism and bromocriptine therapy in prolactinoma [7, 8]. Finding out the etiological reason for pituitary insufficiency is difficult after the development of empty sella. Our patient neither had a history related with pituitary adenoma, nor used any treatment for pituitary adenoma or hypothyroidism; furthermore, her $27 \mathrm{yr}$ earlier obstetrical history was typical for Sheehan's syndrome.

The typical course of Sheehan's syndrome is the appearance of GH and PRL deficiency, followed by gonadotropin deficiency, and then, thyrotropin deficiency and finally, corticotropin deficiency $[1,2,6]$. The severity of pituitary damage determines the timing of the onset and the magnitude of pituitary failure. Acute hypopituitarism may occur immediately after delivery or different degree of pituitary failure develops over a period of time $[1,2]$. Patients with failure to lactate and amenorrhea in early postpartum period do not seek medical attention until life-threatening symptoms and signs of hypothyroidism, and more importantly, adrenal insufficiency supervened. The majority of patients with Sheehan's syndrome are diagnosed after appearance of hypothyroidism or adrenal insufficiency in our region as in our case. The period between time of diagnosis and the date of last delivery was $27 \mathrm{yr}$ Ozbey et al. reported that the mean duration between diagnosis and last delivery was $10.6 \mathrm{yr}(0.5-29 \mathrm{yr})$ in the 40 patients with Sheehan's syndrome [1]. It was reported as $13.9 \mathrm{yr}(6-30 \mathrm{yr})$ by Sert et al. and $6.1 \mathrm{yr}$ by Goswami et al. in their series [2,3].

Adrenocortical carcinomas may be non-functional and may be discovered incidentally or it may be diagnosed while investigating the symptoms and signs of different endocrine syndromes or suspicious adrenal masses $[9,10]$. Tumors have a tendency to multiple hormone secretion. In adults with ACC, hypercortisolism and hyperandrogenism are most common endocrine disorders, which exist in $30-40 \%$ and in $20-30 \%$ of patients, respectively $[5,10]$.

In our case, DHEAS, androstenedione and its peripheral converted products such as total and free testosterone levels were high and hirsutism was present. Cushing's syndrome may be combined with androgen hypersecretion in $10-30 \%$ patients with ACC [10]. It has been suggested that DHEAS increase in adrenal adenomas is prevalent and this should be accepted as a marker of malignant tumor [11].

Adrenal adenomas showing a pattern of enzymatic block related to impairment of 21-hydroxylase or 11 $\beta$ hydroxylase have been suggested to be malignant and it could be used to follow up recurrence [9]. We thought that the elevation of $17 \alpha \mathrm{OHP}$ levels suggesting evidence of impairment of 21-hydroxylase enzyme activity was related to ACC in our case. It would be very interesting to study whether germline mutation of 21-hydroxylase gene (CYP21) exists because it may be possible in such cases [12]. But we could not study it for this case. 
There are usually lymph node, lung, liver, abdomen and bone metastases by the time ACC is diagnosed and 5 year survival rate is less than $15-30 \%$ in those patients diagnosed at stage III or IV [10]. Our case was determined at stage 4 , because tumor diameter was $>5 \mathrm{~cm}$ and had distant organ metastases $[5,10]$. The average survival in the cases of ACC is generally 18 months $[5,9]$. The essential treatment of ACC is excision of mass even in the presence of distant organ metastases, after which treatment with mitotane is recommended [5]. Surgical excision of the adrenal mass and mitotane treatment was planned but the patient preferred to continue her treatment at another center. But we have since learned that she died two months after discharge from our hospital and that she in fact did not apply to any medical center for treatment.

\section{References}

1. Ozbey N, Inanc S, Aral F, Azezli A, Orhan Y, Sencer E, Molvalılar S (1994) Clinical and laboratory evaluation of 40 patients with Sheehan's syndrome. Isr J Med Sci 30: 826-829.

2. Sert M, Tetiker T, Kirim S, Kocak M (2003) Clinical report of 28 patients with Sheehan's syndrome. Endocr J 50: 297-301.

3. Goswami R, Kochupillai N, Crock PA, Jaleel A, Gupta N (2002) Pituitary autoimmunity in patients with Sheehan's syndrome. J Clin Endocrinol Metab 87: 4137-4141.

4. Ross NS, Aron DC (1990) Hormonal evaluation of the patient with an incidentally discovered adrenal mass. N Engl J Med 323: 1401-1405.

5. Stratakis CA, Chrousos GP (2000) Adrenal Cancer. Endocrinol Metab Clin North Am 29: 15-25.

6. Kamoi K, Toyama M, Sodo N (1999) A case of Cushing's disease revealed six years after postpartum hypopituitarism. J Clin Endocrinol Metab 84: 27132723.

7. Unluhizarci K, Bayram F, Colak R, Ozturk F, Selcuklu A, Durak AC, Kelestimur F (2001) Clinical case seminar; Distinct radiological and clinical appearance of lymphocytic hypophysitis. J Clin Endocrinol Metab 86: 1861-1864.

8. Dokmetas HS, Selcuklu A, Colak R, Unluhizarci K, Bayram F, Kelestimur F (1999) Pituitary apoplexy probably due to TRH and GnRH stimulations tests in a patient with acromegaly. J Endocrinol Invest 22: 698700 .

9. Mendonca BB, Lucon AM, Menezes CA, Saldanha LB, Latronico AC, Zerbini C, Madureira G, Domenice S, Albergaria MA, Camargo MH (1995) Clinical, hormonal and pathological findings in a comparative study of adrenal cortical neoplasms in childhood and adulthood. J Urol 154: 2004-2009.

10. Latronico AC, Chrousos GP (1997) Adrenocortical tumors. J Clin Endocrinol Metab 82: 1317-1324.

11. Barzon L, Boscaro M (2000) Diagnosis and management of adrenal incidentalomas. $J$ Urol 163: 398-407.

12. Abo K, Sumino K, Nishio H, Hozumi T, Ishida $Y$, Fujieda K, Tajima T, Kazumi T (1999) 21-Hydroxylase deficiency presenting as massive bilateral adrenal masses in the seventh decade of life. Endocr J 46: 817823. 